Nowacka Agnieszka, Smuczyński Wojciech, Woźniak-Dąbrowska Kamila, Lewko Dawid. Altruistic and egoistic behaviors in interpersonal interactions. Journal of Education, Health and Sport. 2021;11(01):40-46. eISSN 2391-8306. DOI http://dx.doi.org/10.12775/JEHS.2021.11.01.004

https://apcz.umk.pl/czasopisma/index.php/JEHS/article/view/JEHS.2021.11.01.004

https://zenodo.org/record/4437642

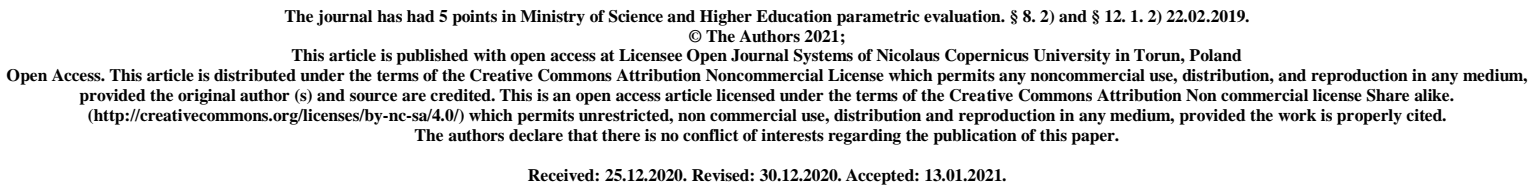

\title{
Altruistic and egoistic behaviors in interpersonal interactions
}

\author{
Agnieszka Nowacka ${ }^{1}$, Wojciech Smuczyński ${ }^{2}$ Kamila Woźniak-Dąbrowska ${ }^{1}$, \\ Dawid Lewko ${ }^{1}$
}

${ }^{1}$ Department of Neurosurgery, Nicolaus Copernicus University Collegium Medicum in Bydgoszcz, Poland

${ }^{2}$ Department of Physiotherapy, Nicolaus Copernicus University Collegium Medicum in Bydgoszcz, Poland

\begin{abstract}
Introduction. Utopian or destructive society? Is it better to be an egoist or an altruist in a group and which factors does it depend on?

Aim. Difficulty in making an unambiguous assessment of social interactions was the reason for conducting a few studies which aimed at identifying factors shaping altruistic and selfish behaviors. Due to the scope of the studies, percentage results relate only to selected social communities.

Materials and methods. The first study aimed at evaluating altruistic behaviors of an individual and of a group and was focused on an analysis of interpersonal interactions between a person who needed help (not calling for it) and a bystander observing the incident. The second experiment evaluated psychologization of confidence and focused on the assessment of interpersonal relations of two participants. The last, third study aimed at evaluating altruistic attitude towards various social relations.

Results. Conducted studies show that there are a lot of factors which determine conscious (financial benefits, empathy) and unconscious (difficulty in interpreting the incident, inadequate intervention, unwillingness to feel responsible for own behavior) development of altruistic and egoistic behaviors in interpersonal interactions.
\end{abstract}

Key words: behavior; interpersonal interactions; psychology. 


\section{Introduction}

Helping behavior is an action which is intended to bring benefits to other person [1]. Benefits can be divided into:

- material (offering money),

- biological (donating own blood),

- psychological (emotional support in misfortunes).

A specific kind of helpful behavior is altruism [1,2], which does not bring any benefits to the helper but can bring him a loss. Interpersonal relationships are based on mutual relations between people and depending on social dependencies, they refer to various relationships between the partners. In altruist society the percentage of people ready to give help should be much higher. Unfortunately, difficulty in interpreting an event or inability to successfully intervene prevent many people from providing help. We behave differently when we provide help to people whom we know (family members, friends) and when the recipient of the help is a complete stranger. In such cases we might be motivated by egoism (financial benefits for providing help), voluntary altruism or moral commitment [2].

In order to identify external factors, shaping altruistic behaviors in interpersonal interactions, the authors performed three studies in selected social groups (passers-by, surveyees).

\section{Materials and methods}

The first study aimed at evaluating altruistic behaviors of an individual and of a group and was focused on an analysis of interpersonal interactions between a person who needed help (not calling for it) and a bystander observing the incident.

The social experiment was conducted in a park on Jana Kasprowicza Alley, in Wroclaw and included two trials. In the first trial the authors expected disinterested help which was to be provided by passers-by (for the purpose of the trial, one of its authors was falling over and pretended to have difficulty standing up). The other trial involved support from passers-by given to a person who required help (for the purpose of the trial one of its authors was falling over and pretended to have difficulty standing up despite being helped by another two authors). The total number of randomly selected respondents of the studies was 120.

The second experiment evaluated psychologization of confidence and focused on the assessment of interpersonal relations of two participants.

The study was conducted in the Market Square in Wroclaw. Two hundred randomly selected respondents were given a survey which consisted of 2 parts. In each two parts the authors asked questions to 100 respondents (50 couples - 50 had known each other before and 50 had not known each other before). The respondents got familiar with instructions of the following game: Two people are staying in two rooms separated from each other with a bullet-proof glass pane. Player 1 has keys for both the rooms and two options to choose: he will open the door of his room, leave the other person and win a prize of 500,000 PLN or he will give the key to the other person by putting it under the glass. Player 2, 
after he has received the key has two options: he will open the door of his room and give the key back to the first person; they both will win 1,000,000 PLN each or he will not give the key back and win a prize of 500,000 PLN.

The instructions slightly changed in the second part: Player 1 has two options to choose: he will open the door of his room and win a prize of 1,000,000 PLN or he will give the key to the other person. Player 2, after he has received the key has two options: either he will open the door of his room and give the key back to the first person; they both will win 500,000 PLN each or he will not give the key back and win a prize of 1,000,000 PLN. It is not possible for Player 1 to open the door of his room and give the key back to Player 2. Opening the door will involve leaving Player 2 and winning a prize (in the first trial - 500,000 PLN and in the second trial-1,000,000 PLN).

It should be emphasized that the respondents wrote their answers on paper slips and the participants in particular pairs did not know decisions made by the other respondents. It was a requirement to identify a real attitude of the respondents towards a theoretical situation in which they might find themselves. After giving their answers, the surveys put the paper slips in a box so none of them knew what decision the other person had made.

The last, third study aimed at evaluating altruistic attitude towards various social relations.

The study was conducted in the area of Karlowice (close to Jana Kasprowicza Alley, in Wroclaw). Randomly selected 80 respondents filled in a short questionnaire. They were given one simple question: Whom would you help in a street? An unconscious young man lying in a street or a limping elderly woman to cross the street? The question would not be difficult to answer due to the given options but what is the studied factor is the question whether the respondents will make a choice and guess the provocation hidden in the question. The aim of the survey was to identify behavioral factors which shape our altruistic approach in social groups - are we more willing to help an elderly limping woman, or a young man who lost consciousness in a street, or both of them?

\section{Results}

An analysis of the results of the first study reveals that in the second trial more passers-by saw the incident and provided help than during the first trial. In the first case, the person who needed help "required" immediate and disinterested support of passers-by; in the second case, there was one mock altruist in the studied social group. Marody and GizaPoleszczuk [3] explain that it is better to be an egoist than an altruist in a group. However, in groups with a greater number of altruists, everyone benefits because many individuals are willing to cooperate, renounce something or make a sacrifice. A decisive model of critical intervention shows what discourages people from giving help [1, 4]. The above analysis allows to conclude that it is easier not to provide help rather than provide it.

Providing help needs fulfilling five requirements:

- bystander must see the incident;

- he must perceive it as a critical situation which requires intervention;

- he must feel responsible for what is going on and for what might happen; 
- he must choose the form of help (great competences usually facilitate making a decision to help, e.g. doctors provide help more frequently than shop assistants)

- he must start acting.

Failure to meet even one requirement might prevent someone from giving help, which indirectly explains why so many people in the study refused help; they either did not meet criteria or did not want to meet them.

In the second trial, bystanders were more willing to intervene due to an extra altruist who needed their support. Other bystanders observing the incident made some people take a decision to help. In the first and second trials, certain people noticed the incident but none of them intervened. It was single passers-by who provided help. It often happened that they saw what was going on and initiated help. The probability of not undertaking any action to help a person requiring help is higher if there are a lot of bystanders [5, 6]. Diffusion of responsibility was first described by Darley and Latane [4], who explained that pressure to initiate any action is distributed among all bystanders of a particular incident. The more bystanders, the less strong pressure each of them feels. Consequently, each person feels less responsible for initiating the action. They observe each other and conclude that nothing has happened so none of them provide help to the person who has fallen down. The phenomenon of diffused responsibility, also called "bystander's apathy" was also analyzed by other authors at a later time. Piliavin and Rodin [7] add that this occurs when the cost of such help is high and refusal to provide the help does not entail any responsibility. When the observed incident has appeared to be clearly unambiguous and its bystanders interpret it as a critical situation, the bystander's apathy is no longer felt; direct requests for help activate passers-by who decide to provide help $[2,8]$.

The first study revealed that shaping all altruistic and egoistic behaviours in a witness to a particular incident depends not only on presence of altruists in the group and ability to properly interpret the incident and effectively intervene but also on the number of other observers. Besides, young people definitely more frequently tend to give help (in the first trial - 11 out of 16 people; in the second trial - 20 out of 30 people), which might imply that age is also a predisposing factor for developing altruistic and egoistic behaviours in interpersonal interactions.

Results of the second study reveal that almost all of the bystanders in the first part, who had and had not known each other previously, were willing to cooperate. In the second part the percentage expressing different decisions considerably changed. It was worthwhile to cooperate in the first part due to huge financial benefits. In the second part, benefits derived from cooperation are smaller than on non-cooperation. Let us analyze the behavior of people in the second part who had known each other before. Despite emotional bonds among the participants of this part, a great number of them, being Players 1, had egoistic tendencies and were ready to leave their partners. In contrast, the latter ones were willing to cooperate. It seems to be interesting but a similar observation can be made for the participants who had not known each other beforehand. A lot of surveys, being Players 1, were driven by their own self-interest and decided to leave their "co-participants". However, almost half of them (Players 2) took a decision to give the key back. Even if one of the players is an altruist, he will depend on the other player's decision. Player 1, who is in possession of the keys, can be driven by an altruistic behavior and help the other person but he must trust that person, 
whereas, Player 2, after receiving the keys, can cooperate with Player 1 or behave egoistically by leaving the "co-participant".

Social dilemmas are connected with co-dependence of individuals - altruistic behavior of one individual affects egoistic behavior of another individual [3, 9]. If we do not take into account the interest of an individual and ascribe egoism to that person, this will make cooperation less productive. However, we should remember that taking the interest of the individual into account may contribute to a huge loss - if the person fails. Thus, shaping altruistic and egoistic behaviors is to some extent based on mutual confidence of individuals. Experience that we gain while having contacts with people allows us to decide to what extent we can trust in them. Confidence is identified with a feeling that the person in whom we trust will take our interest into consideration during any cooperation but it often happens otherwise $[10,11]$. An altruist voluntarily bears costs for another person, whereas an egoist benefits from that. Confidence is related to our own safety. We think rationally and will not trust someone if we do not feel safe with them.

Player 1 faces up to a serious dilemma before taking a decision. If he is motivated by egoism, cooperation for him will be worthwhile only if it is hugely profitable (the first part). He might be motivated by altruism but this time, he will not know what his "co-participant" will be motivated by. It should be pointed out that confidence increases along with developed emotional bonds in a society. With regards to Part 2, in the group of respondents who had known each other before, 10 Players opened the door, whereas in the group of respondents who had not known each other before, as many as 20 Players did it - for fear of their safety, they did not trust their partners and/or were motivated by egoism (receiving more money). In the same part, the second part, Players 2 did not find any reason to trust Players 1 since they depended on them only in the beginning. Thus, it can be concluded that it is more difficult to trust in someone rather than take responsibility for someone else's trust.

Results of the second study confirmed that development of altruistic and egoistic behaviors when an individual cooperates voluntarily depends on the person's own feeling of security and trust towards this individual. If the cooperation between partners is beneficial for both of them, it is highly probable that they will undertake voluntary cooperation, regardless of their motivation, which facilitates solving social dilemmas [3]. Besides, it is easier to obtain help from someone who we are in good relationships with, rather than from a person with whom we do not feel strong social bonds. This relationship enables to explain huge differences for the respondents who had and had not known each other before. According to Wojciszke [1], we are more willing to help members of our own group than strangers. We then feel more responsible for them, and identify their well-being with ours.

An analysis of the third study showed that the majority of respondents were willing to give help to an elderly woman. Only $20 \%$ of them promised to give support to both the people. Some of the surveys stated that they bore in mind their own personal safety while deciding to help. Most of them preferred to help the elderly woman. They claimed they did not know how the unconscious man would react. They said he might have attacked if he had been under the influence of alcohol. Those who decided to help the man claimed that the incident required an immediate intervention, unlike in the incident with the elderly woman, who needed support while crossing the street. The decisive model of critical intervention (Fig 3) partly explains such discrepancies in obtained results. 
Some participants of the study, in fear for their safety and due to lack of confidence, do not want to feel responsible for what might happen to the unconscious man while he is being provided with help. Thus, they are not aware that they could give him such help.

\section{Conclusions}

Conducted studies show that there are a lot of factors which determine conscious (financial benefits, empathy) and unconscious (difficulty in interpreting the incident, inadequate intervention, unwillingness to feel responsible for own behavior) development of altruistic and egoistic behaviors in interpersonal interactions. The aim of the conducted study was to identify factors shaping altruistic and egoistic behaviors in interpersonal interactions on the basis of studied social groups and not to determine what percentage of population will be motivated by a particular factor in a particular situation (in the study, it was not pointed out that percentage results, obtained during experiments, will be applicable for the whole population). In the light of the above, re-conducting the study on a greater number of respondents seems advisable. This will help to determine the percentage of people who develop certain behaviors in selected situations, representative for the whole population.

In the authors' opinion, each individual is motivated by various factors and adopts different attitudes. Due to instilling some values in the upbringing process, possessing to make an independent evaluation of the need of correlations between individuals (the first and third studies) and being aware of the importance of social confidence, facilitating coordination and cooperation (the second study) for the sake of mutual benefits, we can consciously shape our social behaviors $[12,13]$.

\section{References}

1. Wojciszke B. Człowiek wśród ludzi. Zarys psychologii społecznej. Warsaw, WS: SCHOLAR 2004.

2. Kowalczyk S. Człowiek a społeczność: zarys filozofii społecznej. Lublin, QLU: KUL 2005.

3. Marody M, Giza-Poleszczuk A. Przemiany więzi społecznych. Zarys teorii zmiany społecznej. Warsaw, WS: SCHOLAR 2004.

4. Darley JM, Latane B. Bystander intervention in emergencies: Diffusion of responsibility. Journal of Personality and Social Psychology 1968; 8:377-83.

https://doi.apa.org/doiLanding?doi=10.1037\%2Fh0025589

5. Kozyr-Kowalski S. Socjologia, społeczeństwo obywatelskie i państwo. Poznan, POZ: UAM 2004.

6. Frankfort-Nachmias Ch, Nachmias D. Metody badawcze w naukach społecznych. Poznan, POZ: Zysk \& S-ka 2001.

7. Piliavin IM, Rodin J, Piliavin JA. Good Samaritanism: An underground phenomenon? Journal of Personality and Social Psychology 1969; 13:289-99.

https://doi.apa.org/doiLanding?doi=10.1037\%2Fh0028433 
8. Piff PK, Kraus MW, Côté S, Cheng BH, Keltner D. Having less, giving more: The influence of social class on prosocial behavior. Journal of Personality and Social Psychology 2010; 99:771-84.

https://doi.apa.org/doiLanding?doi=10.1037\%2Fa0020092

9. Ramsey G. Can altruism be unified? Studies in History and Philosophy of Biological and Biomedical Sciences 2016; 56:32-8.

https://www.semanticscholar.org/paper/Can-altruism-be-unified-

Ramsey/787d6994f1f2d9260b5fde7c0f1df575f9f0e659

10. Scharf K, Smith SL. Relational altruism and giving in social groups. Journal of Public Economics 2016; 141:1-10.

https://www.sciencedirect.com/science/article/abs/pii/S0047272716300718?via\%3Dihub

11. Feiler DC, Tost LP, Grant AM. Mixed reasons, missed givings: The costs of blending egoistic and altruistic reasons in donation requests. Journal of Experimental Social Psychology 2012; 48:1322-8.

https://www.marshall.usc.edu/sites/default/files/tost/intellcont/Feiler\%20Tost\%20Grant\%202 012\%20JESP-1.pdf

12. Yi R, Pickover A, Stuppy-Sullivan AM, Baker S, Landes RD. Impact of episodic thinking on altruism. Journal of Experimental Social Psychology 2016; 65:74-81.

https://www.ncbi.nlm.nih.gov/pmc/articles/PMC5096404/

13. De Waal FBM. Putting the altruism back into altruism: The evolution of empathy.

Annual Review of Psychology 2008; 59:279-300.

https://pubmed.ncbi.nlm.nih.gov/17550343/ 